\title{
SENSITIVITY TESTS FOR THE POLYMYXINS
}

\author{
BY
}

\author{
S. R. M. BUSHBY
}

From the Wellcome Research Laboratories, Beckenham, Kent

(RECEIVED FOR PUBLICATION AUGUST 11, 1954)

Although the value of polymyxins $B$ and $E$ in the treatment of infections with Gram-negative bacilli is well recognized, they are not usually used unless the causal organisms are insensitive to antibiotics with wider activity. In consequence, sensitivity tests for them are not common laboratory procedures and it is not generally appreciated that the usual methods are not entirely satisfactory.

Judged from experience with the commoner antibiotics, organisms often appear insensitive to the polymyxins when tested by the agar diffusion method, yet the dilution (inclusion) method may show them to be fully sensitive. This latter method too can give very variable results, especially when a fluid medium is used, and on a solid medium the strain may often appear to consist of resistant and sensitive variants when in fact it is homogeneous. The discrepancies in both of these methods are probably due to the fact that the mode of action of the polymyxins differs from those of the more commonly used antibiotics, and studies of the action have revealed two important facts.

First, the polymyxins are always bactericidal (Brownlee and Bushby, 1948; Brownlee, Bushby, and Short, 1952) and bacteriolytic (White, Alverson, Baker, and Jackson, 1949; Bushby, 1952), apparently through being absorbed by the cell membrane and altering its permeability. They thus act in a manner similar to the cationic detergent, cetyltrimethylammonium bromide (Bushby, 1952; Few and Schulman, 1953).

Secondly, the minimum bactericidal concentration of the polymyxins depends upon the number of organisms present (Brownlee et al., 1952) due to the fact that a certain quantity of polymyxin is expended in killing each organism. The amount absorbed is therefore roughly proportional to the sensitivity of the strain and to the number of organisms present (Bushby, 1952), but the relationship is complicated by the fact that complete saturation of the organisms is not necessary for the bactericidal effect. Incidentally the organisms do not have to be living for this absorption to occur.
From these facts it follows that it is not possible $\frac{\text { ? }}{2}$ to state an exact sensitivity figure for any given? organism without defining the size of the inoculum $m_{i}^{\infty}$ used in the test. Swift and Bushby (1951) showedthat the apparent sensitivity of a strain of Haemo- $N$ philus influenzae ranged from 0.8 units to 25 units윽 per ml., depending upon the size of the inoculum.-

The following experiments illustrate the poors correlation between the apparent sensitivities when measured by the diffusion and dilution methods. $\vec{c}$ Three different-sized inocula of eight organisms of different genera were used.

\section{Technique}

Diffusion Method.-Filter paper discs $8 \mathrm{~mm}$. in⿳亠े⿵冂卄 diameter were impregnated with 40 units and 100 units $\frac{2}{\mathrm{Q}}$ of polymyxin B per disc by adding $0.05 \mathrm{ml}$. of an aqueous solution of the antibiotic. Two discs, one of each $\overrightarrow{\vec{O}}$ concentration, were placed on nutrient agar plates 3 infected with the three different-sized inocula. The inocula were from an 18-hour broth culture diluted to give growths of colonies that were heavy confluent, just confluent, and separate. Plates $9 \mathrm{~cm}$. in diametero were used and $0.3 \mathrm{ml}$. of the diluted culture was addedo to $3 \mathrm{ml}$. of molten nutrient agar and poured over a base layer $3 \mathrm{~mm}$. thick. After 18 hours' incubation ato $37^{\circ} \mathrm{C}$. the diameters of the zones of inhibited growth were measured, the measurement including the diameter of the disc.

Dilution Method.-Polymyxin B was added asepticallyo to molten nutrient agar in twofold increasing concen $\overline{\bar{N}}$ trations ranging from 0.15 to 160 units per ml., distrion buted in $5 \mathrm{ml}$. quantities into tubes and sloped.

By this procedure a number of sets of tubes con taining graded concentrations of polymyxin werew obtained and one set was used for each of the three inocula of the eight organisms. One loopful $(3 \mathrm{mmo}$ diameter) of diluted culture was spread over the surface् of the medium, and the three dilutions of each organism? were such that after 18 hours' incubation growth in the control tubes (without antibiotic) was of the same orde $\bar{E}$ as that of each of the three types obtained on the plates in the diffusion method. The concentration of poly $\frac{\mathcal{D}}{\mathbb{D}}$ myxin which inhibited $90 \%$ or more of growth, a® compared with the control tube, was recorded. 


\section{Results}

These are shown in Table I. The disc containing the higher concentration of the antibiotic was intended to produce conditions similar to those recommended by Thompson (1950), i.e., that moderately resistant, moderately sensitive, and fully sensitive organisms should show varying-sized zones of inhibition, and the disc with the lower concentration to fulfil the recommendations of Fairbrother and Martyn (1951), i.e., that only organisms sensitive to therapeutic concentrations of the antibiotic should show a zone of inhibition. For the latter 40 units were chosen because they produced no zone of inhibition with Streptococcus pyogenes. The table shows that it is only within

TABLE I

RESULTS OF TESTS WITH POLYMYXINS B AND E

\begin{tabular}{|c|c|c|c|c|c|}
\hline \multirow{2}{*}{ Organism } & \multirow{2}{*}{$\begin{array}{c}\text { Dilution } \\
\text { of } \\
\text { Culture }\end{array}$} & \multirow{2}{*}{$\begin{array}{c}\text { No. } \\
\text { of } \\
\text { Colonies }\end{array}$} & \multirow{2}{*}{$\begin{array}{c}\text { Method of } \\
\text { Serial } \\
\text { Dilution in } \\
\text { Nutrient } \\
\text { Agar } \\
\text { Minimum } \\
\text { Concen- } \\
\text { tration } \\
\text { Inhibiting } \\
90 \% \\
\text { Growth }\end{array}$} & \multicolumn{2}{|c|}{$\begin{array}{l}\text { Diffusion Method } \\
\text { (Zone } \\
\text { Diameter-mm.) }\end{array}$} \\
\hline & & & & $\begin{array}{c}40 \\
\text { Units } \\
\text { per } \\
\text { Disc }\end{array}$ & $\begin{array}{c}100 \\
\text { Units } \\
\text { per } \\
\text { Disc }\end{array}$ \\
\hline $\begin{array}{l}\text { Sh. paradysen- } \\
\text { teriae }\end{array}$ & $\begin{array}{l}10^{-1} \\
10^{-2}\end{array}$ & $\begin{array}{c}+++ \\
++\end{array}$ & $\begin{array}{l}2.5 \\
0 \cdot 6\end{array}$ & $\begin{array}{l}13 \\
15 \cdot 5\end{array}$ & 16 \\
\hline S. typhosa .. & $\begin{array}{l}10^{-1} \\
10^{-2} \\
10^{-4}\end{array}$ & $\begin{array}{c}++ \\
++\end{array}$ & $\begin{array}{l}0.5 \\
5.0 \\
2.5 \\
1.25\end{array}$ & $\begin{array}{l}11 \\
11 \\
12 \\
15\end{array}$ & $\begin{array}{l}23 \\
15 \\
18 \\
21\end{array}$ \\
\hline Bact. coli $\ldots$ & $\begin{array}{l}10^{-1} \\
10^{-3} \\
10^{-5}\end{array}$ & $\begin{array}{c}+++ \\
++ \\
+\end{array}$ & $\begin{array}{l}5.0 \\
2.5 \\
0.6\end{array}$ & $\begin{array}{l}12 \\
13 \\
14\end{array}$ & $\begin{array}{l}13 \\
16 \\
18\end{array}$ \\
\hline $\begin{array}{l}\text { Kleb. pneu- } \\
\text { moniae }\end{array}$ & $\begin{array}{l}10^{-1} \\
10^{-3} \\
10^{-5}\end{array}$ & $\begin{array}{c}+++ \\
++ \\
+\end{array}$ & $\begin{array}{l}5 \cdot 0 \\
2 \cdot 5 \\
2 \cdot 5\end{array}$ & $\begin{array}{l}\text { Nil } \\
11 \\
11\end{array}$ & $\begin{array}{l}14 \\
18 \\
19\end{array}$ \\
\hline Ps. aeruginosa & $\begin{array}{l}10^{-1} \\
10^{-3} \\
10^{-5}\end{array}$ & $\begin{array}{c}+++ \\
++\end{array}$ & $\begin{array}{r}20.0 \\
10.0 \\
5.0\end{array}$ & $\begin{array}{l}11 \\
14 \\
14\end{array}$ & $\begin{array}{l}15 \\
18 \\
20\end{array}$ \\
\hline St.pyogenes & $\begin{array}{l}10^{-1} \\
10^{-2}\end{array}$ & ++ & 50.0 & Nil & 14 \\
\hline S. aureus & $\begin{array}{l}10^{-1} \\
10^{-8} \\
10^{-6}\end{array}$ & $\begin{array}{c}+++ \\
++\end{array}$ & $\begin{array}{l}>160 \\
>160\end{array}$ & $"$ & Nil \\
\hline P. vulgaris & $\begin{array}{l}10^{-1} \\
10^{-2} \\
10^{-4}\end{array}$ & $\begin{array}{c}+++ \\
++ \\
+\end{array}$ & $\begin{array}{l}>160 \\
>160 \\
>160\end{array}$ & ", & ", \\
\hline
\end{tabular}

$+++=$ Heavy confluent. $++=$ Just confluent. $+=$ Separate colonies.

narrow limits that the recommendations of Fairbrother and Martyn are achieved, for although by the deliberate arrangement of the concentration St. pyogenes can be made to appear insensitive, there is no correlation between the sizes of the zones of inhibition and the sensitivities of the more sensitive strains as shown by the dilution method. With the higher 100 unit concentration of polymyxin the correlation is no better, for although the diffusion method places $S t$. pyogenes in the correct order of sensitivity when the small inoculum is used, with the heavier inoculum St. pyogenes appears to be more sensitive than Bact. coli.

\section{Discussion}

The failure of the diffusion method with the polymyxins can be attributed to three main causes. First, there is the difficulty of controlling the size of the inoculum; secondly, because of their large molecular size and highly non-specific absorbing properties the polymyxins diffuse very poorly; and thirdly, the area of the zone of inhibition varies with the rate of multiplication of the organism, because when there is an appreciable increase in the number of organisms before the slowly diffusing antibiotic reaches them, the effect is the same as would be obtained by using a heavier inoculum. Another factor which will also cause variations in the area of the zone is the continued absorption of the diffusing polymyxin by the killed organisms, and the larger the inoculum the more pronounced will be this effect. The importance of the size of inoculum in the diffusion method for the common antibiotics has, however, been stressed by Fairbrother and Martyn (1951), but they recommend using a heavy inoculum, which would be most misleading with the polymyxins.

In the experiments with the dilution method the level of polymyxin which inhibits $90 \%$ or more of the growth was taken as the minimum inhibiting concentration. This was done because the endpoint is often not sharp, due to a few colonies growing in concentrations several times greater than that which kills most of the organisms, and it is these colonies which can give the impression that a culture is heterogeneous. Re-testing of these apparently less sensitive organisms shows them, however, to be no more resistant than the organisms killed by the lower concentrations, and their survival was presumably due to the fact that having escaped the action of the polymyxin, perhaps because they were in a clump, they then multiplied until they were too numerous for the concentration of residual unabsorbed polymyxin. The ability of organisms already dead to continue to absorb polymyxin would also add to this shielding effect. When a fluid instead of a solid medium is used the organisms that survive for the same reason will multiply and cause the strain to appear less sensitive than it really is.

That $S t$. pyogenes should show some sensitivity may be surprising, for the polymyxins are usually regarded as being specifically active against the Gram-negative bacilli, with the exception of Proteus vulgaris, but it is unlikely that any organism is completely resistant. Small inocula of St.pyogenes 
are sensitive to concentrations of 50 units per $\mathrm{ml}$. and some strains of Staphylococcus aureus to 200500 units per $\mathrm{ml}$. $P$. vulgaris, in spite of its high resistance, is nevertheless killed by concentrations of 10,000 units per $\mathrm{ml}$. Infections with these less sensitive organisms may be capable of being controlled by topical therapy with the polymyxins, but it is only those due to the more sensitive organisms that can respond to parenteral therapy. It is therefore important that the test should be sufficiently accurate to detect these differences. In spite of its limitations the dilution method can be standardized sufficiently to give fairly consistent and unequivocal results, and a recommended method for routine procedure, together with a comment on the standardization of the polymyxins, is given in the addendum.

\section{Summary}

Because the diffusion sensitivity method is unsatisfactory with the polymyxins, a serial dilution method in solid medium, using small inocula, is recommended, and the concentration of polymyxin which kills $90 \%$ of the organisms can be conveniently accepted as the minimum inhibitory concentration.

REFERENCES

Brownlee, G., and Bushby, S. R. M. (1948). Lancet, 1, 127. Brownlee, G., and Bushy, (1952). Brit. J. Pharmacol.' 7, 170

Bushby, S. R. M. (1952). The Chemotherapy and Pharmacology of the Polymyxins. Ph.D. thesis.

Fairbrother, R. W., and Martyn, G. (1951). Journal of Clinical Pathology, 4, 374.

Few, A. V., and 'Schulman, J. H. (1953). J. gen. Microbiol., 9, 454.

Swift, P. N., and Bushby, S. R. M. (1951). Lancet, 2, 183 .

Thompson, B. A. (1950). Journal of Clinical Pathology, 3, 118.

White, H. J., Alverson, C. M., Baker, M. J., and Jackson, E. R. (1949). Ann. N.Y. Acad. Sci., 51, 879.

\section{A D D E N D U M}

Recommended Technique.-The polymyxin is added to molten nutrient agar, which is then sloped and inoculated with about 50 organisms. After 18 hours' incubation that concentration which inhibits approximately $90 \%$ or more of the growth is taken as the end-point. In practice, the medium can be sterilized after addition of the polymyxin by heating at $100^{\circ} \mathrm{C}$. for $\mathbf{2 0}$ minutes and stored in the refrigerator for at least six months without significant loss of potency. Tubes containing 2, 5, 10, 25, and 50 units per ml. are usually sufficient for routine use. With most organisms one standard loopful ( $3 \mathrm{~mm}$.) of a $10^{-5}$ dilution of an 18-hour broth culture is a suitable inoculum.

Standardization of the Polymyxins.-This may cause confusion, because the polymyxins are among the few antibiotics still standardized on a unit basis. The units are arbitrary ones and reference standards of known unitage are used by the manufacturers for assaying unknown samples. The purest samples of polymyxins B and E have contained approximately 10,000 units per mg., and as these were crystalline they may have been $100 \%$ pure. When the potency of polymyxin is expressed on a weight basis, as it is in the United States, it is assumed that there are 10,000 units per mg. or 1 unit $=$ $0.1 \mu \mathrm{g}$. The polymyxin B available in this country is issued on a unit basis, and as it is usually about $70 \%$ pure it contains only about 7,000 units per mg.

For the sensitivity test the polymyxin can be taken from therapeutic material, either by dissolving a weighed sample in water or by dissolving the whole contents of the container in a known volume. In aqueous solution the polymyxins are stable for at least six months when kept in the refrigerator. 